\title{
Ruthenium Red and Lanthanum Nitrate a Possible Tracer and Negative Stain for Scrapie "Particles"?
}

\author{
H. K. Narang \\ Medical Research Council Demyelinating Diseases Unit, \\ Newcastle General Hospital, Newcastle upon Tyne, England \\ Received November 26, 1973; Accepted April 16, 1974
}

Summary. The cucumber- or sausage-shaped particles described before in scrapie rat and natural scrapie sheep are also found in scrapie mouse with the use of ruthenium red and lanthanum nitrate. It is suggested that they have a nucleic acid core surrounded by a coat of acid polysaccharide. The plasma membranes are pair of unit membranes.

Key words: Ruthenium Red - Lanthanum Nitrate - Nucleic Acid Core - Polysaccharide.

\section{Introduction}

The true nature of the transmissible agent of scrapie has attracted considerable interest, especially as to whether it is a virus or some other, as yet unknown, type of replicating agent not containing nucleic acid (Alper et al., 1966; Alper et al., 1967). A number of different particles have been seen in the natural and experimental disease (David-Ferreira et al., 1968; Bignami and Parry, 1971), and more recently Narang et al. (1972) and Field et al. (1972) described cucumber or sausage-shaped particles which appear to correspond with the estimated size of scrapie particles deduced from recent infectivity filtration experiments (Hunter, 1972). These particles were rather difficult to find. Experiments were designed to increase the effective width by using impregnating techniques. The Fontana method has been used for silver impregnation to view bacteria, particularly in spirochaetes, by light microscopy; this technique adds to the effective width of the spirals. Ruthenium red and lanthanum nitrate electron dense tracer have also been used to fill the extracellular spaces (Hirano and Dembitzer, 1969). Ruthenium red, initially introduced into electron microscopy by Luft (1966), appears to bind to certain acid mucopolysaccharides or acid mucoproteins in the presence of osmium tetroxide. In the present preliminary study lanthanum nitrate and ruthenium red were used for tracing the scrapie agent.

\section{Materials and Methods}

10 Webster Swiss (WS) white mice, two to three weeks old, were inoculated intracerebrally with $0.1 \mathrm{ml}$ of $10^{-1}$ mouse adapted scrapie agent and the same number were inoculated with normal mice brain. They were killed at various stages of disease and the brains were pre-fixed in glutaraldehyde as described by Narang (in press). Tissue was also fixed with added $1 \%$ lanthanum nitrate or $500 \mathrm{ppm}$ ruthenium red in glutaraldehyde for 2 hrs. Tissue was rinsed with sodium cacodylate buffer containing some amounts of lanthanum nitrate and ruthenium red and then post-fixed in $1 \%$ osmic acid with trace elements in same concentration as before for 2 hrs and embedded in epon. 


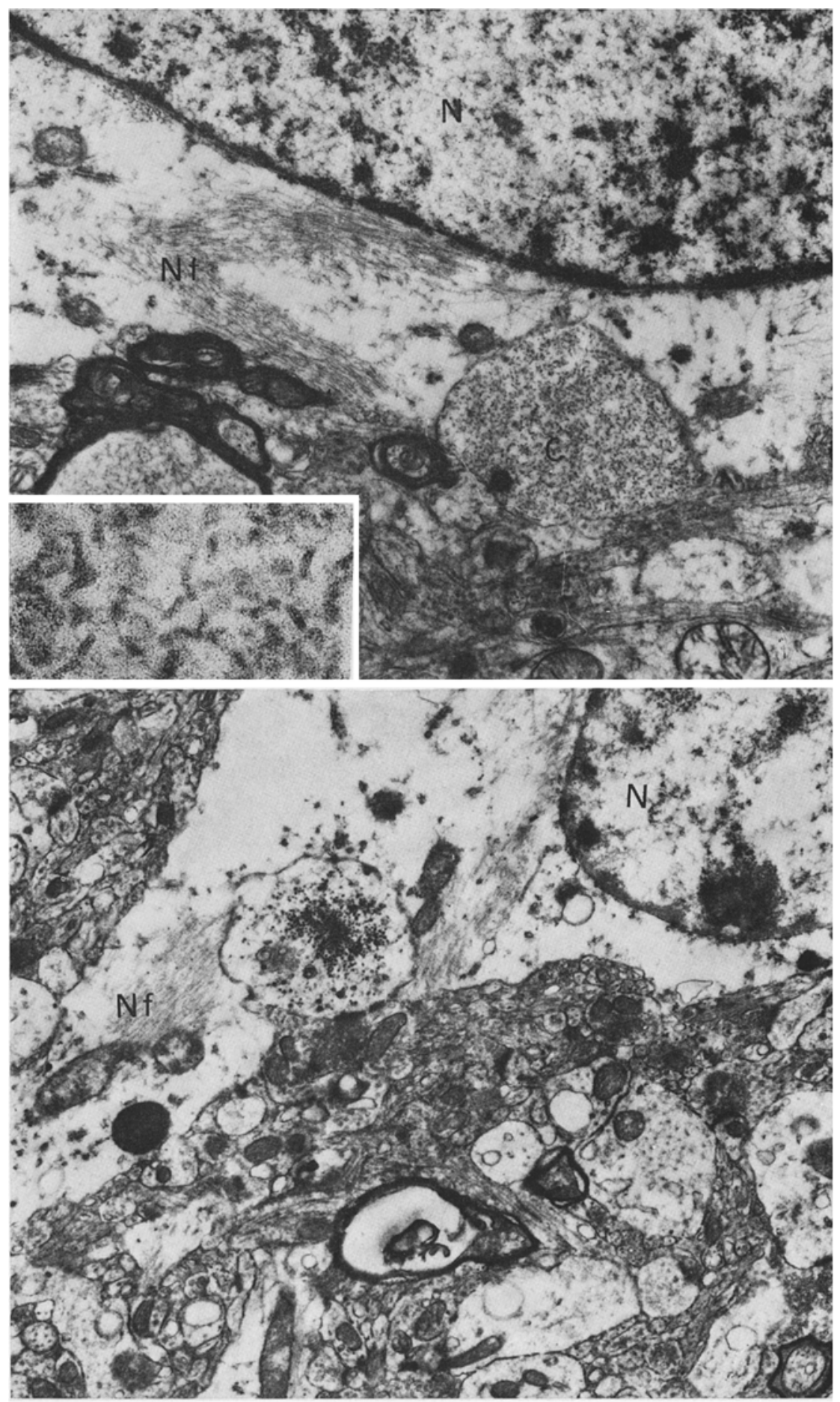

Figs. 1 and 2 


\section{Results}

An important change noticed during this work in normal and experimental animals was the resolution of "unit membranes". Each of these appeared as a pair, unit membranes. These paired unit membranes were seen in cell wall, mitochondria, nuclear membrane, endoplasmic reticulum, and will be described in details elsewhere.

Inclusion bodies were seen both in normally fixed scrapie mouse brain and in lanthanum or ruthenium impregnated sections (Figs. 1 and 2). After lanthanum and ruthenium impregnation the particles were clearer and easier to find since their effective width increased from $20 \mathrm{~nm}$ to $22-24 \mathrm{~nm}$. Besides increasing the effective size of particles, the deposit of the trace element round the particles increased the contrast due to its negative staining properties. These colonies were seen in post-synaptic nerve terminals (Figs. 2 and 3 ). At high magnification the impregnated specimens appeared to contain filaments, probably twisted tubules, with a clear central hole (Fig.4). On the other hand in normally fixed. scrapie material a large number of discrete rod or cucumber-shaped particles were seen to possess a central dark linear core (Fig. 1 inset). Vesicles about $100-110 \mathrm{~nm}$ in diameter containing a fine granular material were found associated with the particles (Figs. 2-4). Glutaraldehyde fixed neurotubules are about 22-27 mu in diameter with a lumen about $13-15 \mathrm{~m} \mu$. With added trace elements the overall diameter increased to $30-32 \mathrm{~m} \mu$ with a wall about $6-7 \mathrm{~m} \mu$ thick which reduces the lumen to only $10 \mathrm{~m} \mu$ (Fig.5). The outer and inner walls are dense and contain 13-14 globules, or 6-7 globules respectively (Fig. 5).

\section{Discussion}

In electron micrograph of material which has been fixed with potassium permanganate or an aldehyde plasma membrane appears as a triple-layered structure consisting of two electron dense layers with an electron lucent layer between them. It is 15 years since Robertson (1959) named this triple structure unit membrane. Fernandez-Moran (1962), Roots and Johnston (1964), Sjöstrand (1963) and many other electron microscopists have seen indication of substructure in membranes which are not compatible with the classical bi-molecular leaflet of the unit membrane concept. In the present study in mitochondria it has been shown that each dense membrane of the triple membrane is composed of two dense layers separated by an electron lucent layer, each about $25 \AA$ thickness suggesting that each unit membrane of Robertson (1959) is in fact a pair. Substructure hitherto not clearly described but long suspected may underlie membrane

Fig.1. Scrapie mouse parietal cortex normally fixed in glutaraldehyde and osmic acid showing astrocyte nucleus $N$ and nerve terminal filled with accumulation of small elongated cucumbers $C$; density is similar to neurofilaments $N f . \times 16200$

Inset. High power view of Fig.1, showing discrete rod or cucumber-shaped particles. Note central core in some of them. $\times 54000$

Fig. 2. Section from scrapie mouse parietal cortex fixed with added $500 \mathrm{ppm}$ ruthenium red. Astrocyte nucleus $N$ is seen at top of the picture and presynaptic terminal is full of particles denser as compared to neurofilaments $N f . \times 13500$ 


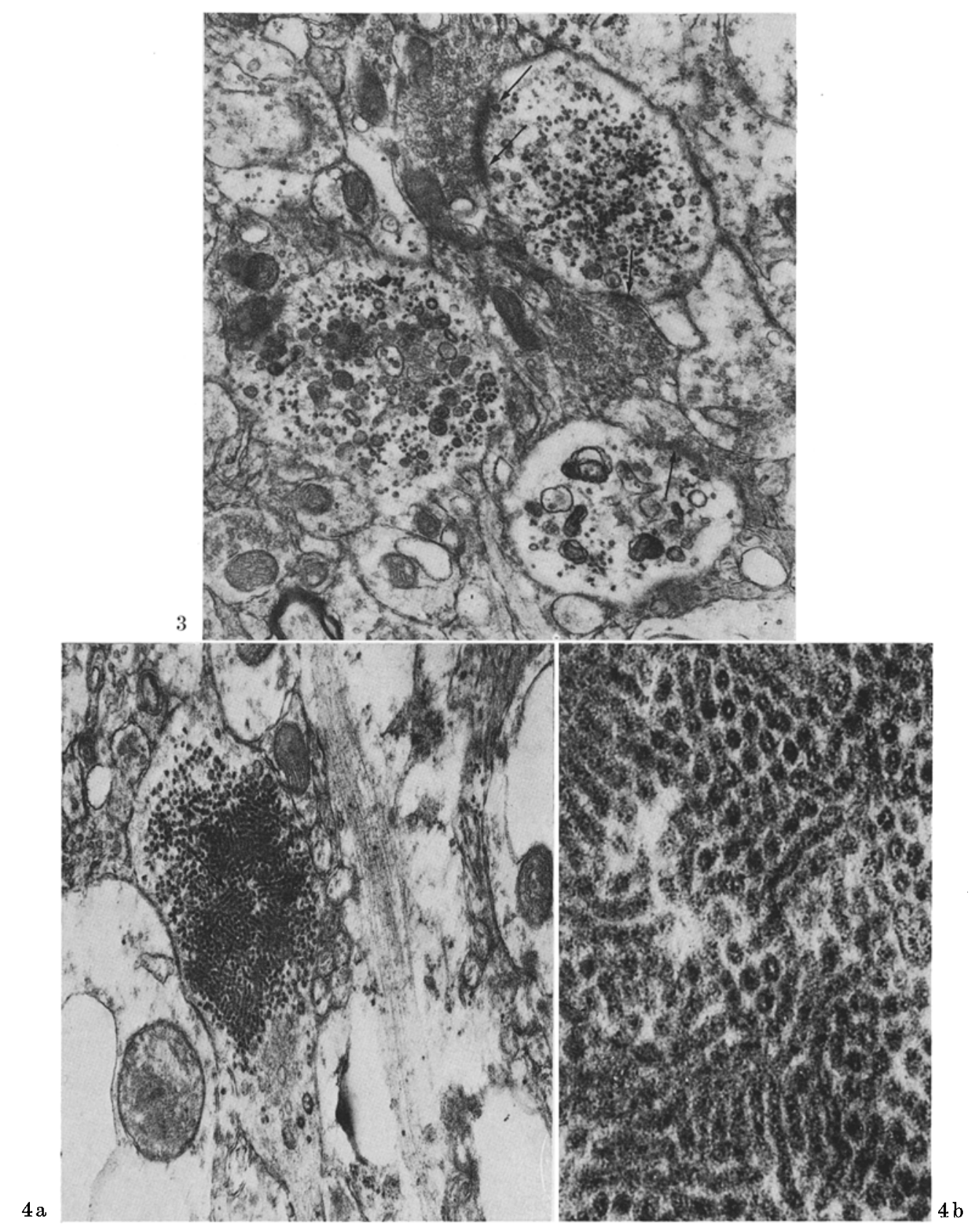

Fig. 3. Section from scrapie mouse brain cortex, fixed with added $1 \%$ lanthanum nitrate. Note the groups of particles associated with vesicles. Arrows indicate synaptic cleft. $\times 27000$

Fig.4. Nerve terminal from scrapie mouse thalamus fixed with added ruthenium red showing tubulofilament structure of the particles. Some appear to be twisted, shown by arrows. Group of vesicles are seen at the top centre. $\times 54000$

Inset. High power of Fig. 4 showing detailed nature of these particles, $\times 149500$ 


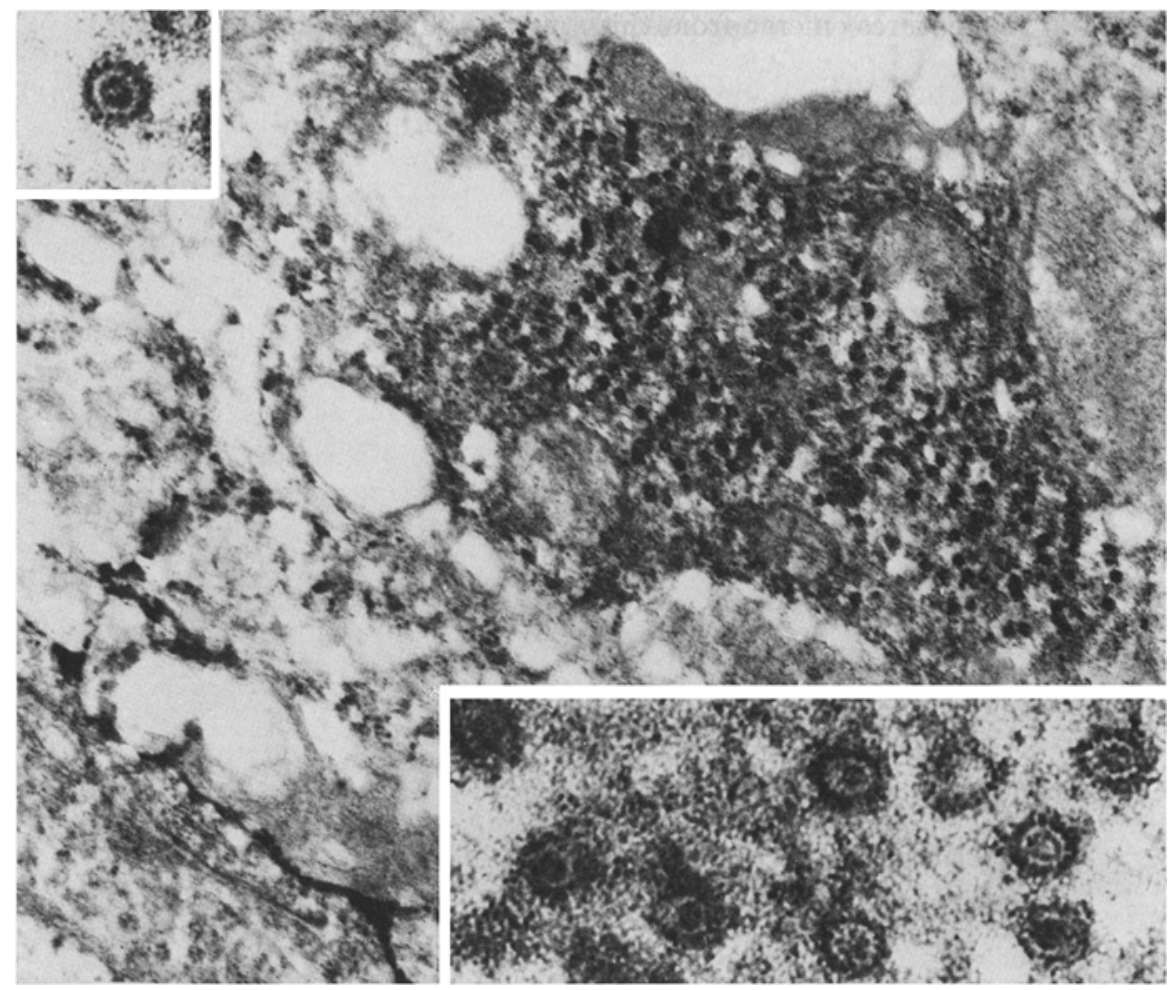

Fig.5. Electron micrograph from mouse thalamus. Note ruthenium red in extracellular spaces and a group of densely stained neurotubules. $\times 30000$

Inset. High magnification of neurotubules. Top left inset is well cut transverse section. Note two dense cores and their substructure. $\times \mathbf{2 4 3 0 0 0}$

architecture and explain the models of molecular organisation in membrane. Keeping in mind the ultrastructural differences brought about by the ruthenium red, it is certain that the tracer fixes membranes better when compared to conventional methods. Cucumber- or sausage-shaped particles described before in scrapie rats (Narang et al., 1972; Field et al., 1972) and in natural scrapie sheep (Narang, in press). The present study of scrapie mouse brain revealed similar particles. The tubular particles in the impregnated specimens differed from cucumber- or sausage-shaped particles seen in normally fixed tissue from the same brain material. Their filamentous and twisted tubular nature in impregnated tissue may be due to overlapping. These particles were not seen in control animals and are clearly distinguished from neurotubules and neurofilaments. Ruthenium red binds to acid mucopolysaccharides and acid mucoproteins in the presence of osmium tetraoxide giving a discrete fine grain stain (Luft, 1966). It is an ionic complex of molecular weight about 860 carrying a net charge of +6 (Fletcher et al., 1961). The high charge and polariability of the cation contributes to the strong binding during the osmium reaction, and it seems reasonable to presume that the increased diameter of the stained particles is due to adsorption of ruthenium red onto an acid polysaccharide outer coat. 
Important features emerge from this study.

1. Membranes are paired unit membranes.

2. Particles of the order of the estimated size of scrapie agent are seen in scrapie mouse brain.

3. They possess a central dark linear core and might indeed represent an infective nuclei acid core.

4. Nuclei acid core is surrounded by thick acid polysaccharide.

The viral nature of the particles is further supported by the association of vesicles with the particles. It is rather difficult to pronounce upon the exact nature and origin of vesicles; they are probably smooth endoplasmic reticulum, a condition previously described in regions of virus replication (Bell et al., 1971; Boulton et al., 1971). It is therefore suggested that these vesicles may be sites of viral replication although perhaps some of the precursors may be formed elsewhere.

The chemistry of lanthanum nitrate is not well understood, but it appears to behave like ruthenium red. Further work on similar lines might show a relationship between these particles and disease or infectivity.

\section{References}

Alpers, T., Cramp, W. A., Haig, D. A., Clarke, M. C.: Does the agent of scrapie replicate without nucleic acid ? Nature (Lond.) 214, 764-766 (1967)

Alpers, T., Haig, D. A., Clarke, M. C.: The exceptionally small size of the scrapie agent. Biochem. biophys. Res. Commun. 22, 278-284 (1966)

Bell, T. M., Field, E. J., Narang, H. K.: Zika virus infection of the central nervous system of mice. Arch. ges. Virusforsch. 35, 183-193 (1971)

Bignami, A., Parry, H. B.: Aggregations of 35 nanometer particles associated with neuronal cytopathic changes in natural scrapie. Science 171, $389-390$ (1971)

Boulton, P. S., Webb, H. E., Fairbairn, G. E., Illavia, S. J.: An electron microscopic study of Lanot virus in tissue culture of the non-neuronal cells of mouse brain. Brain 94, 403-410 (1971)

Cruickshank, R. (ed.): Medical Mierobiology, Staining Methods, chapter 45, pp. 643-680 (1965)

David-Ferreira, J. B., David-Ferreira, K. L., Gibbs, C. J., Morris, J. A.: Scrapie in mice: ultrastructural observations in the cerebral cortex. Proc. Soc. exp. Biol. (N. Y.) 127, $313-320(1968)$

Fernandez-Moran, H.: Cell-membrane ultrastructure: low temperature electron microscopy and X-ray diffraction studies of lipoprotein components in lamellar systems. Circulation 26, $1039-1065(1962)$

Field, E. J., Narang, H. K.; An electron microscopic study of scrapie in the rat: further observations on "inclusion bodies" and virus-like particles. J. neurol. Sci. 17, 347-364 (1972)

Fletcher, J. M., Greenfield, B., Hardy, J., Scargill, D., Woodhead, J.: J. chem. Soc. 1961, $2000-2006$

Hirano, A., Dembitzer, H. M.: The transverse bands are a means of access to the periaxonal space of control myelinated nerve fibers. J. Ultrastruct. Res. 28, 141-149 (1969)

Hunter, G. D.: Scrapie prototype slow infection. J. infect. Dis. 125, 427-440 (1972)

Luft, J. H.: Fine structure of capillary and endocapillary layer as revealed by ruthenium red. Fed. Proc. 25, 1773-1783 (1966)

Narang, H. K., Shenton, B. K., Giorgi, P. P., Field, E. J.: Scrapie agent and neurons. Nature (Lond.) 240, 105-106 (1972) 
Narang, H. K.: An electron microscopic study of natural scrapie sheep brain: further observations on virus-like particles and paramyxovirus-like tubules. Acta neuropath. (Berl.) (in press)

Robertson, J. D.: The ultrastructure of cell membranes and their derivative. Biochem. Soc. Symp. 16, 3-43 (1959)

Roots, B. I., Johnston, P. V.: Neurons of ox-brain nuclei: their isolation and appearance by light and electron microscopy. J. Ultrastruct. Res. 10, 350-361 (1964)

Sjöstrand, F. S.: A comparison of plasma membrane, cytomembranes, and mitochondrial membrane elements with respect of ultrastructural features. J. Ultrastruct. Res. 9, $561-580(1963)$

H. K. Narang

University of Newcastle

Newcastle General Hospital

Westgate Road

Newcastle upon Tyne, NE4 6BE

Great Britain 